\title{
Safety Incentive Program for Construction Project: Case Studies of Several Construction Projects in Klang Valley, Malaysia
}

\author{
Nor Haslinda Abas ${ }^{1, *}$, Mohammad Hafiz Nurahim ${ }^{1,2}$, Norazam Yasin $^{1}$, Muhamad Hanafi Rahmat ${ }^{1}$ \\ ${ }^{1}$ Jamilus Research Centre, Faculty of Civil Engineering and Built Environment, Universiti Tun Hussein Onn Malaysia, \\ 86400 Batu Pahat, Johor, Malaysia \\ ${ }^{2}$ Aneka Bena M.N. Sdn Bhd, No. 56 \& 56A, Jalan Cantik 4, Taman Pelangi Indah, 81800 Johor Bahru, Johor, Malaysia
}

Received April 26, 2020 ; Revised May 28, 2020; Accepted June 23, 2020

Copyright $@ 2020$ by authors, all rights reserved. Authors agree that this article remains permanently open access under the terms of the Creative Commons Attribution License 4.0 International License

\begin{abstract}
This paper presents a study on the effectiveness of safety incentive programs on construction sites in Klang Valley, Malaysia. Five construction projects that implemented safety incentive program were selected as case studies for this research. Interviews with the safety personnel for each project were conducted. The findings show that all selected case study projects had implemented a safety incentive program in different ways, such as using safety awards, housekeeping, unsafe behavior reporting, etc. However, there were issues and weaknesses in implementing these programs as raised by the respondents, which included miscommunication between the employee and the management, unsatisfactory safety awareness by employees, and so on. Some of the suggestions given by the respondents to minimize these problems included implementing communication courses, promoting programs through security campaigns and management involvement. The findings of this study provide information on the implementation of a safety incentive program at the construction site, and can also be used as a source of reference within the site safety management on how to properly implement the program.
\end{abstract}

Keywords Safety Incentive Program, Construction, Occupational Safety and Health, Safety Culture

\section{Introduction}

The Malaysian construction industry plays an important role in the country's economic and socio-economic growth [1]. However, it is classified as the most dangerous industry due to its work environment as measured by data on worker deaths, workers' compensation, injuries, and mortality rates [2]. According to statistics released by the Department of Occupational Safety and Health (DOSH), the construction industry is one of three high-risk sectors besides the manufacturing and agriculture sectors. Statistics produced by DOSH have shown that, in 2019 (until October), the fatalities recorded in the construction industry was 72 out of 214 recorded fatalities in all industries, with the percentage of $33.6 \%$ [3]. The high fatality rate in Malaysian construction industry indicates the crucial need to reduce the number of accidents in construction.

There were extensive safety and health laws enacted by DOSH against the construction industry in Malaysia such as the Occupational Safety and Health Act (OSHA) 1994, Factory and Machinery (FMA) Act 1967, and Building Operations and Works of Engineering Construction 1986. However, the level of awareness and legal compliance is still lower than expected [4]. This is evident from the high number of accidents recorded in the construction industry each year.

One of the major causes of occupational accidents in the construction industry is due to unsafe workers' actions and behaviors [5]. According to Zaini [6], some construction workers refused to wear Personal Protective Equipment (PPE) while working on construction sites. It is suggested that to minimize the rate of accidents at construction sites, management approaches should be proposed as the construction industry involves complex processes. Therefore, it is necessary to identify appropriate approaches to enhance safety performance in improving the construction industry image by minimizing hazards at construction sites [7].

One of the suggested strategies is to incorporate incentive programs into construction projects. Safety 
incentive programs refer to programs that reward workers for achieving certain goals related to workplace safety [8, 9]. Some studies show that safety incentive programs can improve many safety performances at the construction site, such as by Goodrum and Gangwar [9], Hassan and Jha [10], Hinze and Gambatese [11], and Hinze et al. [12]. This is a program that provides workers with a reward system for improving safe work practices and reducing the number of reported injuries and illnesses [9].

Previous research had shown that companies that implemented security incentive programs had lower time-lost rates than companies that did not practice security incentive programs [9]. By implementing a safety incentive program, management will be rewarded with improved safety performance while employees will be motivated by recognition and recognition [13]. Safety incentive programs can be divided into two categories, Injury-based incentive programs and Behavior-based incentive programs. In other words, this is the implementation of security programs such as Behavior-Based Safety (BBS) or Injury-Based Safety (IBS) with the involvement of the reward system [12].

These programs can be implemented in a passive way such as through rewarding employees for non-injury periods, as well as in proactive ways such as proactive safety incentive programs that reward workers for actions such as making safety recommendations, identifying or correcting hazards, participating in the program health or serve on the security committee or task force [14]. However, in the context of the Malaysian construction industry, there have been no studies on safety incentive programs. Therefore, this study aimed to study the implementation of safety incentive program among selected contractors in Klang Valley, Malaysia. Three (3) objectives have been identified, as follows:

i) To investigate the common safety incentive program in the construction project;

ii) To identify the problem faced in implementing safety incentive program; and

iii) To propose the strategies to minimize the problem faced in implementing the safety incentive program.

\section{Methods}

The 'unit of analysis' in this research is interpreted as the civil engineering or building construction projects, which implement a safety incentive program at a construction site. With such a design, this study was conducted with five (5) construction companies in the Klang Valley, Malaysia. For inclusion in this study, the projects must have the following criteria: (a) the main contractor of each project is a Grade 7 (G7) contractor with a G7 Grade license approved by the Construction Industry Development Board (CIDB) Malaysia (note that G7 contractors are allowed to operate civil engineering construction and building construction for an unlimited amount), and (b) implement a safety incentive program in the project. The organization for this case study was selected by the author who at the same time had a good relationship with the author. This helped to gain access to the company for detailed study.

Semi-structured interviews were conducted, involving the participation of one representative from each construction project. The targeted respondents were the Safety and Health Officer (SHO) or Site Safety Supervisor (SSS). SHO / SSS was selected as interviewees because they were responsible for the safety and health of the construction site. All the SHOs and SSSs interviewed were competent persons registered with the Department of Occupational Safety and Health (DOSH) of Malaysia. Participants were committed to doing the project research and had reasonable experience and credibility in specific areas. The questions raised during the interview were: (i) what are the common security programs run by your company? (ii) what are the problems/problems with running a security incentive program? (iii) do you have any suggestions for reducing this problem?

Interviews took between 30 and 60 minutes for each participant at their workplace. Interviews were digitally recorded for accurate conversation information and to prevent data loss as not all could be written during interviews. Each interview was numbered and labeled with the interviewer's name (coded) and the interview date. Interview transcripts were analyzed by two different researchers for comparison of study results. The background of the interviewees is shown in Table 1.

Table 1. Specific data of Column/Row

\begin{tabular}{|c|c|c|c|c|}
\hline Interviewee & Project ID & Interviewee's job position & $\begin{array}{c}\text { Academic } \\
\text { qualification }\end{array}$ & Working experience \\
\hline Interviewee A & Project A & Safety and Health Officer (SHO) & Bachelor's Degree & More than 5 years \\
\hline Interviewee B & Project B & Site Safety Supervisor (SSS) & Diploma & More than 5 years \\
\hline Interviewee C & Project C & Site Safety Supervisor (SSS) & Diploma & Between 1 to 5 years \\
\hline Interviewee D & Project D & Site Safety Supervisor (SSS) & Certificate & Between 1 to 5 years \\
\hline Interviewee E & Project E & Safety and Health Officer (SHO) & Diploma & Between 1 to 5 years \\
\hline
\end{tabular}




\section{Results}

\subsection{Project A: Construction of High Rise Office Building, Kuala Lumpur}

\subsubsection{Types of Safety Incentive Program}

Interviewee A stated that the security incentive program was an incentive program for certain short-term programs or activities related to $\mathrm{OSH}$ at the construction site. Implementation of a safety incentive program at selected construction sites depends on the request from the construction management team. Not all safety courses were involved in incentive program plans.

On this project site, the construction site was divided into several specific sites. Each distribution site was placed under the responsibility of a designated sub-contractor. The safety performance of each site would be evaluated by the main contractor's safety committee for safety award requirements. Sub-contractors with satisfactory safety performance on their construction site would be awarded the "Best Construction Site Award". There were several criteria required for the award such as the cleanliness of the construction site and others.

For individual awards, employees will be evaluated based on their commitment to improving safety at the construction site such as attending safety programs and their attitude towards safety while doing work in the workplace. This was known as the "Best Employee Award" held every month.

\subsubsection{Problems Related to Safety Incentive Program}

Among the challenges faced by the management during the implementation of the safety incentive program was the lack of response given by the construction workers to the implementation of the incentive program. Most of the employees were more interested in working to earn a monthly salary than pursuing incentives based on their safety performance at the construction site.

Besides that, the communication problem between the employee and the management also contributed to this factor. Most construction workers were foreign workers from countries such as Myanmar, Bangladesh, and others. The majority of them did not understand the local language. Thus, it was difficult to reach the knowledge to the employees about the implementation of the safety incentive program effectively.

\subsubsection{Suggested Ways to Facilitate Incentive Program}

Interviewee A stated that he was having trouble communicating about the safety incentive program with foreign workers. This problem was resolved by the involvement of top executives in implementing alternative programs related to improved communication such as language courses and so on.

\subsection{Project B: Construction of Apartment Building, Cyberjaya}

\subsubsection{Types of Safety Incentive Program}

According to Interviewee B, there were several safety programs related to the type of safety incentive program. Interviewee B also added safety programs including 'Housekeeping' and 'Injury Report' were involved for recognition and recognition.

Housekeeping practices have become one of the most popular safety programs in the construction industry that emphasize the cleanliness of construction sites for the prevention of accidents and illnesses. Poor housekeeping practices can lead to an increased risk of injury or illness at work. On selected construction sites, employees would be performing housekeeping before 5 pm daily. Occasionally, the safety committee would conduct a weekly audit to evaluate the cleanliness of the construction site. To encourage this practice, the main contractor's safety committee had implemented a Safety Award that focuses on the cleanest construction site in a construction project. Sub-Contractors with the cleanest construction site would be given a safety award.

In response to the incentive safety-based program, the main contractor's safety committee also introduced a reward system for reporting unsafe workforce behaviors that contribute to construction hazards. In this system, a reward of RM50 would be given to the workers for reporting unsafe worker behavior at the construction site. Meanwhile, fines would be imposed on workers with unsafe behavior at the construction site. For example, a fine of RM100 would be imposed on workers found smoking at work. The selected construction site also offers a monthly security award in honor of the employee.

\subsubsection{Problems Related to Safety Incentive Program}

Although there are safety incentive programs implemented, there are still issues with safety awareness among construction workers. For example, some workers have behavioral problems such as smoking at work, dumping garbage everywhere and so on. This means that safety awareness among workers is still low. The security rewards or penalty incentive system still cannot attract some workers with safety awareness at the construction site.

Interviewee B also mentioned about the communication problems between workers and construction project safety committees. There was no problem with workers from Indonesia, Bangladesh and Pakistan as they all understand the local language and English. Communication issues arose between workers from Myanmar. One of the objectives of the security incentive program was to promote safety awareness through a reward system. However, this objective cannot be achieved if communications related problems occur between foreign workers and the safety committee. 


\subsubsection{Suggested Ways to Facilitate Safety Incentive Program}

Due to unsatisfactory safety awareness among workers, Interviewee B suggested that the reward system for reported unsafe behavior required some reforms by raising money for rewards and fines as a motivational tool for workers to increase safety awareness among construction workers.

To minimize communication-related problems, language courses, especially international language courses such as English, should be conducted for workers who did not understand English, to increase their awareness of safety through the security incentive program.

\subsection{Project C: Construction of Office Building, Kuala Lumpur}

\subsubsection{Types of Safety Incentive Program}

In the opinion of the respondent, the safety-based incentive system was only implemented in some safety programs, which was not widely implemented in the construction project. Toolbox-meeting was part of the safety incentive component. At selected construction sites, toolbox-meetings were held weekly on Monday morning. This was a weekly assembly that concentrated on OSH on construction sites. At the toolbox-meeting, recognition would be given to employees who had identified or reported hazards at the construction site.

In another safety program, Interviewee $\mathrm{C}$ stated the safety committee had also applied a reward system to workers for reports of unsafe behavior at the construction site. Meanwhile, penalties will be imposed on workers for unsafe behavior in the workplace. From the perspective of the respondent, it was not advisable to reward employees for several reasons. Respondents prefer to receive non-work-related rewards such as gifts in the form of Personal Protective Equipment (PPE) depending on the specific recipient field at the construction site. For example, recipients who perform their duties in the area with high decibel sound would be given an Ear Plug as a hearing aid. However, the respondent stated that no reward was given to the workers for the housekeeping activities held daily at 11 am.

\subsubsection{Problems Related to Safety Incentive Program}

Interviewee $\mathrm{C}$ only mentioned the lack of communication among construction workers on the construction site. He said it was difficult to promote a security incentive program for all workers in construction projects because some of them did not understand the local language fluently.

\subsubsection{Suggested Ways to Facilitate Safety Incentive Program}

According to Interviewee D, there were some safety programs related to the incentive system. At selected construction sites, each sub-contractor needed to implement daily housekeeping in their construction site. Recognition in the form of a safety award would be given to the cleanest construction sites. Besides that, the best employee would be selected every 3 months for the Safety Award. Selection for awards depended on the safety performance of the employee in the construction site such as PPE, their commitment to safety toolbox-meeting, and so on.

For a new employee, the safety committee took responsibility to implement the Safety Induction Program which was one of the division's safety programs. New employees were asked to participate in these programs as an introduction to OSH before performing their work on the construction site. Upon completion of the program, the employee would receive a certificate of attendance and this certificate would be used to obtain a work permit that allowed the employee to perform a job at the construction site.

In the selected construction project, safety campaigns were introduced to increase safety awareness among construction workers. This campaign was inserted with the incentive element by rewarding employees or obstacles through security quizzes and so on.

\subsubsection{Problems Related to Safety Incentive Program}

Communication problems between foreign workers and management are highlighted as key issues in raising safety awareness through safety incentives programs. Some employees do not understand what a safety incentive program is and how does it work to raise awareness about safety.

\subsubsection{Suggested Ways to Facilitate Safety Incentive Program}

Interviewee D suggested that in selected construction projects, employees were divided into several teams. Each team would have one of the most experienced leaders in the workplace and can understand the local language fluently. Therefore, the information on safety promoted through the safety incentive program could be clearly explained to them.

\subsection{Project E: Construction of Shopping Mall at Bukit Bintang, Kuala Lumpur}

\subsubsection{Types of Safety Incentive Program}

According to Interviewee $\mathrm{E}$, the main contractor of the selected construction site introduced a safety point-based assessment to all sub-contractors on this site. Points would be awarded for the sub-contractors to focus their attention on safety performance. For example, this refers to sub-contractors for hazards or unsafe behaviors reported by their employees. The highest-rated subcontractor among the subcontractors in the construction project would be 
awarded the 'Safety Award'. For individual awards, the best employees would be selected every month based on criteria such as attending safety programs and more.

\subsubsection{Problems Related to Safety Incentive Program}

Interviewee $\mathrm{E}$ said one of the challenges when implementing a security program was communication between several foreign workers and the security committee. Communication problems were usually related to language problems because all information about the security program reached only a small number of foreign workers.

\subsubsection{Suggested Ways to Facilitate Safety Incentive Program}

To address issues related to communication as mentioned earlier, Interviewee E suggested that employers should provide programs that facilitate employee understanding of safety-based incentive programs such as promoting incentives based on safety programs through security campaigns or posters. The security committee can also promote security incentives programs using various languages on posters.

\section{Discussion and Conclusions}

Incentives in the construction industry are approaches to achieve the goals of construction projects by motivating contractors to produce better overall project performance [16]. Sulzer-Azaroff et al. [15] noted that safety performance at the construction site could be enhanced by the demonstration of incentives. The incentive approach included in the safety program is also known as the Safety Incentive Program [16].

Table 2 shows a summary of interviews for research on safety incentive programs implemented at several construction sites. From the analysis of selected case studies, it was found that all the sites and contractors of the selected case study had implemented a safety incentive program, in the form of 'safety awards' to their employees. Safety awards are one of a kind of safety incentive programs to reward employees for their commitment to improving safety performance at construction sites. Besides, 'reward for housekeeping' and 'reward for unsafe act' are also safety incentive approaches implemented by most selected case study projects. From the analysis, it can be seen that all selected construction projects have implemented more than one safety incentive program or approach.
Meanwhile, poor communication is a major issue related to the implementation of safety incentive programs identified in all selected case study projects. There are several sources of communication problems on the site such as work stress, high employee and employee attitudes, misinterpretations of high command, poor employee communication skills, fear of staff talking, misunderstandings of body language and hand signals between supervisors and employees, etc. [17]. In this study, the main reason for the problems raised by interviewees was because of closed lines of communication between management and employees [18] and language barriers especially when communicating with foreign workers [17]. According to Aksorn and Hadikosumo [18], each workplace should use open communication between management and employees, so that employees are encouraged and motivated to report on unsafe work practices and hazardous environments for management attention. This ensures the success of the safety incentive program implemented. Meanwhile, concerning language adjustments, it is difficult to raise safety awareness through incentives system related to safety programs if workers especially foreign workers do not understand the guidelines or information on security incentive programs. As a result, the results of the implementation of the safety incentive program were not as expected. Researchers suggested that the safety incentive program is not a one-off venture, and should continue to be promoted and delivered.

As poor communication has become one of the key issues in implementing a safety incentive program, all interviewees have suggested that effective communication is required by providing language courses to employees, by providing a leader system for employees and by using various languages such as digital signage to promote this program. It is also important for senior management to ensure that the safety incentive program implemented is comprehensive and accessible to all employees involved in construction projects. Management can play a bigger role in promoting safety incentives to a high level of perception. For example, discussions on safety issues between supervisors and employees give them timely feedback [16]. In addition, some solutions that can be suggested to improve communication problems on the construction site such as avoiding noisy-environment communication, improving honesty between employees and employers, providing workshops to develop relationships between employers and employees, employers providing language lessons, excellent motivation to increase workers' confidence in communication and others [17]. 
Table 2. Summary of analysis of the interview

\begin{tabular}{|c|c|c|c|c|c|}
\hline & \multicolumn{5}{|c|}{ Case study project } \\
\hline & Project A & Project B & Project C & Project D & Project E \\
\hline \multicolumn{6}{|c|}{ Types of safety incentive program implemented at construction site } \\
\hline Safety award/recognition & $\sqrt{ }$ & $\sqrt{ }$ & $\sqrt{ }$ & $\sqrt{ }$ & $\sqrt{ }$ \\
\hline Reward for housekeeping & $\sqrt{ }$ & $\sqrt{ }$ & & & $\sqrt{ }$ \\
\hline Reward for unsafe act reported & & $\sqrt{ }$ & $\sqrt{ }$ & & $\sqrt{ }$ \\
\hline Reward for safety induction & & & & $\sqrt{ }$ & \\
\hline Reward for safety campaign & & & & $\sqrt{ }$ & \\
\hline \multicolumn{6}{|c|}{ Problems of the implementation of safety incentive program implementation } \\
\hline Poor communication & $\sqrt{ }$ & $\sqrt{ }$ & $\sqrt{ }$ & $\sqrt{ }$ & $\sqrt{ }$ \\
\hline Safety awareness & & $\sqrt{ }$ & & & \\
\hline \multicolumn{6}{|c|}{ Suggested ways to facilitate problem of safety incentive program } \\
\hline Involvement of top management & $\sqrt{ }$ & & & & \\
\hline Reinforcing an effective communication & $\sqrt{ }$ & $\sqrt{ }$ & $\sqrt{ }$ & $\sqrt{ }$ & $\sqrt{ }$ \\
\hline Increasing reward to the employee & & $\sqrt{ }$ & & & \\
\hline Promoting through safety campaign & & & $\sqrt{ }$ & & $\sqrt{ }$ \\
\hline
\end{tabular}

It is hoped that this study will provide information on the implementation of safety incentive programs at construction sites. Barriers to this safety incentive program have been identified and these improvements can be applied to existing safety incentive programs. The findings of this study provide information on the implementation of safety incentive programs at construction sites, and can also serve as a source of reference in site safety management on how to properly implement the program.

Findings from this study indicate that most organizations implement safety incentive programs as they motivate and instill a culture of safety among employers and workers. Motivation can be defined as an effort in action to meet the needs or desires that come from within or outside the individual, to drive work-related behaviors and to determine shape, direction, interest, and time [19, 20]. To maximize profits, organizations often adopt workplace motivation strategies by increasing motivation and productivity, minimizing attendance and income, and retaining talented and skilled workers [21]. Future research is sought to identify the relationship between the implementation of safety incentive programs and the enhancement of safety performance.

\section{Acknowledgements}

The authors would like to thank the Research Fund E15501, Research Management Centre, Universiti Tun Hussein Onn Malaysia for supporting this research.

\section{REFERENCES}

[1] M. H. Jaafar, K. Arifin, K. Aiyub, M. R. Razman, M. Ahmad. A review of occupational safety and health $(\mathrm{OSH})$ accidents and contributing factors in construction industry, Journal of Food, Agriculture and Environment, Vol.13, No.2, 238-244, 2015.

[2] H. Y. Chong, T. S. Low. Accidents in Malaysian construction industry: statistical data and court cases. International Journal of Occupational Safety and Ergonomics: JOSE, Vol.20, No.3, 503-13, 2014.

[3] DOSH. Accident Statistic, Online Available from https://www.dosh.gov.my/index.php/statistic-v/occupationa l-accident-statistics-v/occupational-accident-statistic-2020

[4] A. R. A Hamid, W. Z. W. Yusuf, B. Singh. Hazards at Construction Sites, Proceedings of the 5th Asia-Pacific Structural Engineering and Construction Conference (APSEC 2003), August 26-28, 2003.

[5] N. C. Berek, T. Suwandi, W. Purnomo. Internal Factors That Influence Unsafe Acts on Construction Workers, Dama Academic Scholarly Journal of Researchers, Vol.2, No.3, 57-61, 2017.

[6] S. A. Zaini. 23 kes kemalangan di tempat kerja direkodkan, Online available from https://www.sinarharian.com.my/arti cle/42194/EDISI/Perak/23-kes-kemalangan-di-tempat-kerja -direkodkan

[7] A. Bakri, R. M. Zin, M. Misnan, A. Mohammed. (2006). Occupational Safety and Health (OSH) Management Systems: Towards Development of Safety and Health Culture, 6th Asia-Pacific Structural Engineering and Construction Conference, September 5-6, 2006.

[8] F. Ghasemi, I. Mohammadfam, A. R. Soltanian, S. Mahmoudi, E. Zarei. Surprising incentive: an instrument for prmoting safety performance of construction employees, Safety and Health at Work, Vol.6, No.3, 227-232, 2015. 
[9] P. M. Goodrum, M. Gangwar (2004) Safety Incentives - A study of their effectiveness in construction, Professional Safety, 24-34, 2004.

[10] A. Hassan, K. N. Jha. Safety incentive and penalty provisions in Indian construction projects and their impact on safety performance, International Journal of Injury Control and Safety Promotion, Vol.20, No.1, 2013.

[11] J. Hinze, J. Gambatese, Factors that influence safety performance of specialty contractors, Journal of construction Engineering and Management, Vol.129, No.2, 2003.

[12] J. Hinzel. Safety incentives: do they reduce injuries? Pract Period Struct Des Constr, Vol.7, 81-84, 2002.

[13] F. A. Zulkefli, N. Ulang, F. Baharum. Construction Health and Safety: Effectiveness of Safety Incentive Programme, SHS Web of Conferences, 1-6, 2014.

[14] Anon. Designing Safety Incentive Programs That Work, Professional Safety, American Society of Safety Engineers, Illinois, 2015.

[15] Sulzer-Azaroff, T. C. Harris, K. B. McCann Beyond training: organizational performance management techniques. Occupational Medicine (Philadelphia, Pa.), Online available from

http://www.scopus.com/inward/record.url?eid=2-s2.0-0028 411642\&partnerID=tZOtx3y1
[16] R. S. Permuth, M. Sodexo, M. W. Gazica. Improving Workplace Safety with Recognition and Rewards Programs A How-To Guide for Long-Term Behavior Change, Online available from https://docplayer.net/10161092-Improvingworkplace-safety-with-recognition-and-rewards-programs-a -how-to-guide-for-long-term-behavior-change-sodexomotiv ation.html

[17] A. Olanrewaju, Y. T. Seong, F. K. Lee. Roles of communication on performance of the construction sector. Procedia Engineering, Vol. 196, 763 - 770, 2017.

[18] T. Aksorn, B. H. W. Hadikusumo. Critical success factors influencing safety program performance in Thai construction projects. Safety Science, Vol. 46, 709-727, 2008.

[19] C. Bao, I. Nizam. The impact of motivation on employee performance in the electronics industry in China. International Jourlan of Accounting \& Business Management,Vol. 3. 2015.

[20] N. Mamuye. Statistical assessment of employee's turnover and its causes: In the case of Moret and Jiru Wereda, North Shoa, Amhara, Ethiopia. American Journal of Theoretical and Applied Statistics, Vol. 7, 139-146, 2018.

[21] G. P. Latham, C. C. Pinder. Work Motivation Theory and Research at the Dawn of the Twenty-First Century. Annual Review of Psychology, Vol. 56, 485-516, 2004. 